\title{
The Demise Of Silicon Graphics Explicated By A Structural Functionalist
}

\author{
Nicholas John Robak, Saint Joseph's University, USA
}

Patricia J. Robak, Drexel University, USA

\begin{abstract}
It has been asserted that positivism is the philosophical basis of research in the field of Information Systems by Goles and Hirschheim. This is seen as problematic in an area that undergoes swift and constant change because of its technological nature. The rise and fall of Silicon Graphics Incorporated (SGI) is the focus of this paper. The mechanism for explaining change is the action theory of Talcott Parsons, a structural functionalist, whose theory, in turn, is attacked for the inability to account facilely for change.
\end{abstract}

Keywords: Functionalism, Positivism, Parsons, Change, Paradigm, Information Systems Theory

\section{INTRODUCTION}

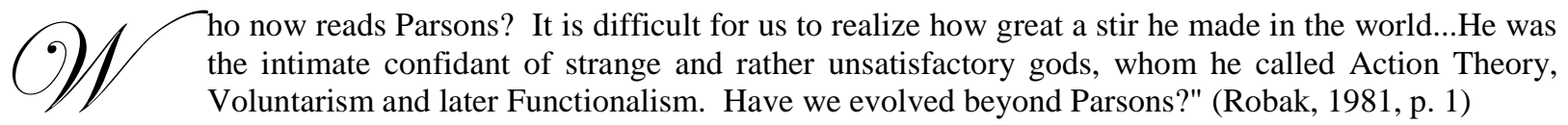

The above quote is a paraphrase of Parsons' from the beginning of The Structure of Social Action, which served as his formal introduction to the world of theory (Parsons, 1937/1968, p. 3). In a flurry of articles in regard to change occurring within the area of Information Systems Development (ISD) it has been asserted that the primary notion of paradigm used in the conception of the field's philosophical discussions is that of Burrell and Morgan (1979) and (Goles and Hirschheim, 2000). It has often been noted that Functionalism (especially that brand espoused by Parsons), is adverse to adequate expressions of change, and indeed one of the major criticisms of Parsons "grand theory" is the inability to allow and account for change.

The purpose of this work is to show how the mechanism of change can be explained using the theoretical formulations of Talcott Parsons within the area of Information Systems. Silicon Graphics was founded in 1982. In July, 1994 it was the cover story of Business Week ("The Gee-Whiz Company") and in August, 1997 it was again the cover story of Business Week ("The Sad Saga of Silicon Graphics"). In 1997 revenues hit an all time high of $\$ 3.6$ billion but profits had fallen to a five-year low of $\$ 78$ million. Revenues declined 15\% in 1998 and losses were recorded at $\$ 457$ million. Its stock, which peaked at $\$ 45.25$ per share on July 12, 1995, plummeted to 46 cents in November of 2005. It was delisted by the New York Stock Exchange that month and filed for Chapter 11 bankruptcy protection.

There were cultural changes occurring (some subtle, others overt) which, in most cases, were ignored or overlooked that led to the dismantling of SGI. These changes, since they were inextricably intertwined with emerging technology, were classic examples of "Cultural Lag" (Ogburn, 1922) which in turn exacerbated the dismembering of SGI. How did this very successful venture turn so bad so quickly? The answer can best be summarized as entropy! A look at its inability to allow for interchanges at the cultural, social system, and personality levels, as have been delineated by Talcott Parsons is what led to rapid deterioration within the Goal Attainment, Latency, and Integration, "functional requisites." 
Change within our society continues to accelerate as can be illustrated in many contemporary works that address the subject (two excellent examples would be Alvin Toffler's Third Wave (1980) and Megatrends (1982) by John Naisbitt). The inexorable rate of change in modern day civilization is well documented as a staple of the present-day world. In ISD and within the field of technology, this rate of change is exacerbated. The decline of SGI begins at the Cultural level.

For entropy to be prevented, there must be a proactive and open interchange among the primary system and all of its supra and infra contemporary systems, as well as subsystems. The environment in today's business world is multifaceted and complex. Also, not to be ignored is the plexus of subsystems that exist within any system.

Fremont E. Kast and James E. Rosenzweig wrote their seminal article "General Systems Theory: Applications for Organization and Management" (Kast \& Rosenzweig, 1972) more than thirty years ago, and it remains a staple for Information Systems' Theorists in their study of "Analysis and Design." Kast and Rosenzweig give a masterful historical and theoretical presentation in a little more than ten short pages of text.

It is the concept of "entropy" that becomes the fundamental tour de force, enabling the authors to vivify the concept of system and its infra and supra interactions. Although "cybernetics" is mentioned explicitly, only once in regard to the concept of "feedback," its impact is latent throughout this paper. If "cybernetics" is indeed based on "Negative feedback" as is stated in the article (Kast \& Rosenzweig, p. 16) and gets its etymology from the Greek kybernetes (steersman, governor, pilot, or rudder), one has to question where SGI went wrong and why it has maintained the wrong direction into serious deterioration.

In the General Systems Theory (GST) article the authors argue that “... questions of organizational effectiveness must be concerned with at least three levels of analysis; the level of the environment, the level of the social organization as a system, and the level of the subsystems (human participants) within the organization" (Kast $\&$ Rosenzweig, p. 20). They go on to state "Perhaps much of our confusion and ambiguity concerning organizational effectiveness stems from our failure to clearly delineate the level of our analysis and even more important, our failure really to understand the relationships among these levels" (Kast \& Rosenzweig, 20).

Nowhere are these "levels" and their "relationships" better articulated than in the works of Talcott Parsons. In an earlier paper, the author uses Parsons to explain a "simple" technological change in the adoption on the mouse and pointing devices in modern computing (Robak, 2001). It is appropriate to now expand this "Parsonian Perspective" to articulate the actions on "entropy" in the analysis of corporate demise.

In the Goles and Hirschheim analysis of paradigm utilization within the area of IS, the authors conclude that it is positivism that is the pervasive paradigm. In addition, change within this paradigm is deemed difficult given any scenario. In an earlier work, Klein and Hirschheim (Boland and Hirschheim, 1987) devote an entire chapter in one of the Wiley Information Systems Series books (1987) to the issue of social change and its impact on Information Systems Development. It is here that the term ISD orthodoxy is encountered as a fundamental paradigm. This exhibits the essential sharing of tenets and is juxtaposed with the "emergence of some radically different approaches to ISD, ones which do not share the same paradigm." Jumping ahead to the 2000 article by Goles and Hirschheim, the application of the Burrell and Morgan framework is utilized to illustrate the viable extant paradigms for the analysis of organizational theory. The paradigms presented are functionalism, radical humanism, radical structuralism, and interpretivist. The research in the field indicates that the functionalist approach is clearly the prevailing one and the positivist perspective generates the "vast majority of information systems research" (Goles \& Hirschheim, 2000, p.254).

This single research perspective is deemed antithetical to change. Indeed, many authors cited in the Goles and Hirschheim article think that it is time to "break the mold" (p. 256) and present viable alternative approaches in order to attain "paradigmatic pluralism" (p. 258) which in turn will lead to more innovative, diverse, appropriate solutions, which would not be quite as difficult given the restrictions imposed by working within the "orthodox" paradigm of positivism and using some method of change imposed by functionalism. 
The focus of this paper is to illustrate and explain how a fundamental change has occurred within the Information Systems field using the example of the rise and fall of Silicon Graphics, Inc.

Parsons uses four levels of action, separate yet interrelated. They are Cultural, Societal, Personality, and Organismic. Parsons explains the relations among the subsystems through the term "cybernetic hierarchy of control" (Turner \& Maryanski, 1979, p. 80). "The systems vary in the amount of "informational control" and "energy" and each level is necessary for control and regulation as well as provision of energy for the next" (Robak, p. 37). The direction is opposite from that taken in the previous paper since "control of the mouse" would emanate from the Organismic because the eye-hand coordination necessary for proper mouse movement is within this realm. In fact, the last two levels (Personality and Behavioral Organism) are realms within the actor; one concerning mental activity and the other physical; and these last two can be bifurcated in the mouse example. However, in the SGI example, the analysis is at the Macro level and the separation is unnecessary.

\section{FUNCTIONAL REQUISITES}

Control of the overall Macro System comes from the Cultural System and works its way to the Social System, then to the Personality System. The "Functional requisites" are Adaptation, Integration, Goal Attainment, and Latency (also known as pattern maintenance). Turner and Maryanski (1979) provide a concise yet thorough description:

\begin{tabular}{|l|l|}
\hline Adaptation & $\begin{array}{l}\text { All action systems must seek resources from the environment, convert them into usable } \\
\text { facilities, and then distribute them to the rest on the system. }\end{array}$ \\
\hline Goal Attainment & $\begin{array}{l}\text { All action systems must set goals, establish priorities and allocate resources in order to } \\
\text { achieve them. }\end{array}$ \\
\hline Integration & $\begin{array}{l}\text { All action systems must maintain coherent interrelationships among their constituent parts, } \\
\text { and inhibit tendencies for abnormalities in the relations among the parts. }\end{array}$ \\
\hline Latency & $\begin{array}{l}\text { All action systems must (a) generate use units that can fit into the system (the problem of } \\
\text { "pattern maintenance"), and (b) reduce tensions within units of the system ("tension } \\
\text { management"). (p. 75). }\end{array}$ \\
\hline
\end{tabular}

"Each of these in turn, rests primarily within a given action system but there are interchanges which allow for the viability of all of the subsystems. The primary adaptive subsystem is the Organismic, the Personality deals with goal attainment, the Social System meets integrative problems, and the Cultural will deal with latency. It is important to remember that the interchanges among these subsystems are what allow for total system efficacy." (Robak, p.38).

Given these overall parameters, how did entropy prevail so as to bring a company with such tremendous momentum to a halt? An additional factor to consider is that of "Cultural Lag," as is articulated by William Fielding Ogburn (Ogburn, 1922). Culture consists not only of social institutions and social ways, but also of the material objects existing and being generated by that society. Objects of technical relevance serve to exacerbate this phenomenon. Rarely was this truer than with the introduction of the Internet and the World Wide Web. Artifacts such as Internet Service Providers (ISPs) and web browsers were introduced, then used, then taken for granted, in a very short period of time. People and companies that could properly capitalize on their usage would quickly gain a competitive edge.

Ironically, the Internet, and the lack of foresight in regard to the Internet on the part of SGI was an integral part of the beginning of its downfall. In 1993 before the arrival of Mosaic, the fortunes of SGI were on the rise and had yet to reach their zenith. As of yet there were no user-friendly browsers and the information highway was yet to be connected. Work at SGI proceeded as usual without giving the potential development of the "super network" the 
proper recognition, an oversight which would signal the onset of decline of the high-end, high resolution, 3-D graphics, workstations which were, at the time, considered by many to be the finest in the industry, and the mainstay of the company.

This would be a misjudgment at the Cultural level (in Parsonian terms) and, in the field of technological development, the culture is in most rapid flux and needs to be attentively monitored so as not to allow competition to gain any advantage. This was one of many oversights by the management of SGI at this level. Initially, SGI could attribute its success to a keen awareness of the technological culture of the time. This awareness diminished as other elements in the "cybernetic hierarchy" took precedence and we can see that the Social System and the Personality were given hegemonic status rather than maintaining their proper relational position relative to their location in the "cybernetic hierarchy." As SGI was prospering and their products (servers, workstations) considered superior to all others in the field, the focus of their leadership changed away from the Cultural level and the success of their "Social System" permitted the individuals at the helm to slip into a presumptiveness which induced them to put too much emphasis on the Personality level. To depart from Parsons for a moment, they simply became too "full of themselves" and allowed for too much emphasis on their own wants.

In 1993, President Clinton and Vice-President Gore paid Silicon Graphics a visit at their main headquarters and CEO Ed McCracken was affected as he shared the stage and cameras with them as they praised the technological dominance of the company in their bid to notify the country that the government was going to support research and development in information technology with tax advantages. McCracken was soon named co-chair of Clinton's National Information Infrastructure Advisory Council and thereafter was deeply involved with Washington politics and crafting policies for the government on communication technologies. Both McCracken and chief operating officer Thomas A. Jermoluk became heavily engaged in products and programs which were tangential to the company's core competencies.

As the vision of the company leaders strayed and as personal preferences prevailed over corporate goals the social system (of the company) began to function in an inoperative manner. This makes perfect sense from the Parsonian perspective since it is the Personality level which has Goal Attainment as its "Functional Requisite." Since the "Social System" receives its energy from the "Personality System" interactions at the corporate level will be disrupted according to the Parsonian "Cybernetic Hierarchy of Control." This is indeed exactly what happened. Mistakes at the company level were rampant. SGI became distracted by markets which were peripheral to its primary product line. The company became interested in digital cable television and combined with Time Warner to launch trial interactive television in late 1994. This was at the same time that the Internet was beginning to take off. It failed because of the burgeoning importance of the Internet, which was not given sufficient consideration. At the same time the increasing power of the PC was misjudged. Pretty soon the PC with newly enhanced Intel chips and more powerful operating systems especially Windows NT, were capable of doing many of the complex graphics applications which were at one time the bailiwick of Silicon Graphics workstations.

Traditional business mainstays like inventory management and customer service were inadequately sustained which led to product shortages and customer dissatisfaction. In addition, employee turnover doubled to $20 \%$, an empirical indicator of internal tumult. To further weaken and distract from that which the company did well, Cray Research was acquired at a time when the market for supercomputers was shrinking. This acquisition was more of a distraction and served to sap managerial energy from fundamental tasks needed to assure effective accomplishment of necessary business functions.

As a consequence of the diminishing profits, the company while being overwhelmed and in a state of fiscal disarray, decided to go for higher margins instead of increasing market share. Under pressure to increase sales, four powerful servers were sold to a Russian facility that designed nuclear warheads without proper government clearance. The mistake was more than likely unintentional but a sign of the chaotic developments and lack of control within the company and caused a federal probe, in addition to negative publicity. These are excellent illustrations of the "personality system" imbalances and their consequences on the "social system." There are further examples of the deterioration and the impact of the personality system and its effect on the corporation. 
Jermoluk, the president of SGI, only 37 at the time, was offered the CEO position at Netscape during the summer of 1994. SGI did not want to lose him and countered with a more than $\$ 10$ million offer for four years. He had a "hands-on" management style that was fine for a smaller company but as the company grew, he did not change. Under the pressure the company was experiencing his personality buckled. He set a "frat house" tone which led to puerile acts on his part including "mooning" employees at a party as well as getting drunk and vomiting at a sales meeting. The behavior of McCracken also showed signs of deterioration as he publically showed affection to a young woman who worked in the human resources department at a company party while he was in the midst of his second divorce. This type of behavior from the top management personnel caused ripples throughout the organization and, to be sure, led the employees to question their leadership. Certainly, it accounted in part for the high turnover rate.

After several years of corporate losses SGI dropped McCracken in November of 1997 but not before he negotiated a severance package of more than $\$ 11$ million. In April, 2007 Silicon Graphics named its fourth CEO since 1997. In September, 2006 seventy-five percent of all SGI products were introduced within the prior nine months!

\section{CONCLUSION}

Although the structural functionalism espoused by the social theorist Talcott Parsons is attacked for its inability to account for change, this paper attempts to illustrate just how it can account for an instance of change in one of the areas of society where pervasive and continual change is the norm, information systems development. The topic of change as an integral part of ISD has been grappled with by writers in the field of information systems from the earliest awareness of the field. Several authors have discussed various paradigms within the field and feel that prevailing positivistic perspective deemed the "orthodox" view is least capable of facilely accounting for change within the field. The authors of this paper explain the demise of SGI from "The Gee-Whiz Company" to an inconsequential enterprise which is struggling to remain in existence. In order to do this the authors assess the three levels of analysis (environment, social organization as a system, and the level of subsystems (human participants) within the organization applying the disruption of the "cybernetic hierarchy of control" as detailed by Talcott Parsons in his version of functionalism.

Nick Robak is a professor in the department of Decision \& Systems Sciences at Saint Joseph's University in Philadelphia. He did both his undergraduate and graduate work at the University of Pennsylvania. Originally trained as a sociologist, he began teaching Management Information Systems after attending the AACSB MIS institutes at the University of Minnesota and Indiana University in the mid-1980s. His non-academic "claim-to-fame" is his membership on the 1962 All-American (All-Ukrainian) Collegiate Football Team with Mike Ditka.

Tricia Robak currently teaches in the Finance Department at Drexel University in Philadelphia, PA. She earned a bachelors degree in Economics from Villanova University and a Ph.D. in Finance and Economics from Lehigh University. Areas of interest include international finance, fixed income securities and derivatives. Tricia has also taught at The College of New Jersey and Villanova University.

\section{REFERENCES}

1. Banville, C. \& Landry, M. (1989) Can the field of MIS be disciplined? Communications of the ACM, 32, p. 4860.

2. Boland, R. J., Jr., \& Hirschheim, R. A. (Eds.). (1987) Critical issues in information systems research. Chichester, Great Britain: John Wiley \& Sons.

3. Burrell, G., \& Morgan, G. (1979) Sociological paradigms and organisational analysis. London: Heinemann Books.

4. Cullen, D. (2006) Silicon Graphics goes titsup [online]. The Register. Available from: <http://www.theregister.co.uk/2006/05/08/silicon_graphics_chapter_11/> [Accessed December 2, 2007]. 
5. $\quad$ eWeek. (2005) SGI: Still hanging tough [online]. Available from: <http://www.eweek.com/print_article2/0.1217.a=164706,00.asp > [Accessed November 9, 2005 ].

6. Gilder, G. (1988, April 4) You ain't seen nothing yet. Forbes, p.89-93.

7. Goles, T., \& Hirschheim, R. (2000) The paradigm is dead, the paradigm is dead...long live the paradigm: the legacy of Burrell and Morgan. Omega, 28, p.249-268.

8. Hof, R. (1994) The gee-whiz company. Business Week, July 18, p.57-64.

9. Hof, R. (1997) The sad saga of Silicon Graphics. Business Week, August 4, p.66-72.

10. Naisbitt, J. (1982) Megatrends: ten new directions transforming our lives. London: Futura.

11. Loubser, J. J., Baum, R. C., Effrat, A., \& Lidz, V. M. (eds.) (1976) Explorations_in general theory in social science. (Vols. 1\&2). New York: The Free Press.

12. Kast, F. \& Rosenzweig, J. (1972) General systems theory: applications for organization and management. Academy of Management Journal, December, 1972, p.447-465

13. Klein, H. \& Hirschheim, R. (1987) Social change and the future of information systems development. In R. J. Boland \& R. A. Hirschheim (Eds.), Critical issues in information systems research (p. 275-305). Chichester, Great Britain: John Wiley \& Sons.

14. Martindale, D. (1981) The nature and types of sociological theory. ( $2^{\text {nd }}$ ed.). Boston: Houghton Mifflin.

15. Ogburn, W. (1922) Social change with respect to culture and original nature. New York: B. W. Huebsch.

16. Orlowski, A. (2005) SGI delisted, becomes penny stock [online]. The Register. Available from: <http://www.theregister.co.uk/2005/11/02/sgi_penny_sto> [Accessed December 2, 2007]. Orlowski, A. (2006) SGI chief outlines roadmap out of mortuary [online]. The Register. Available from: <http://www.theregister.co.uk/2006/06/10/sgi_plans/> [Accessed December 2, 2007].

17. Parsons, T. (1951) The social system. Glencoe, IL: The Free Press.

18. Parsons, T. (1968) The structure of social action: A study in social theory with special reference to a group of recent European writers. (Vols. 1\&2). New York: The Free Press. (Original work published 1937)

19. Parsons, T. (1977a) The evolution of societies. Englewood Cliffs, NJ: Prentice-Hall.

20. Parsons, T. (1977b) Social systems and the evolution of action theory. New York: The Free Press.

21. Parsons, T. (1978) Action theory and the human condition. New York: The Free Press.

22. Parsons, T. \& Shils, E.A. (eds.) (1962) Toward a general theory of action. New York: Harper \& Row. (Original work published 1951).

23. Robak, N. J. (1981) An analysis of the present crisis of the Parsonian scientific research program. Paper presented at the Eastern Sociological Society Annual Meeting. NY.

24. Toffler, A. (1980) The third wave. London: Pan Books.

25. Turner, J. H., \& Maryanski, A. (1979) Functionalism. Menlo Park, CA: Benjamin/Cummings.

26. Vance, A. (2006) SGI moves Bishop to avoid checkmate [online]. The Register. Available from: <http://www.theregister.co.uk/2006/02/01/sgi_moves bishop > [Accessed December 2, 2007]. 